\title{
Group-as-a-whole as a context for studying individual behaviour: A group diagnostic intervention
}

\author{
Author: \\ Dirk J. Geldenhuys ${ }^{1}$ \\ Affiliation: \\ ${ }^{1}$ Department of Industrial \\ and Organisational \\ Psychology, University of \\ South Africa, South Africa \\ Correspondence to: \\ Dirk Geldenhuys \\ Email: \\ geldedj@unisa.ac.za \\ Postal address: \\ PO Box 392, UNISA 0003, \\ South Africa \\ Dates: \\ Received: 22 Aug. 2011 \\ Accepted: 30 Mar. 2012 \\ Published: 13 June 2012 \\ How to cite this article: \\ Geldenhuys, D. (2012). \\ Group-as-a-whole as \\ a context for studying \\ individual behaviour: A group \\ diagnostic intervention. \\ SA Journal of Industrial \\ Psychology/SA Tydskrif vir \\ Bedryfsielkunde, 38(2), Art. \\ \#1011, 12 pages. http:// \\ dx.doi.org/10.4102/sajip. \\ v38i2.1011
}

(C) 2012. The Authors.

Licensee: AOSIS

OpenJournals. This work

is licensed under the

Creative Commons

Attribution License.
Orientation: Traditionalists view group interventions from three perspectives: singletons, dyads and whole groups. The focus of this research was on interventions from the third perspective, that of the whole group, using a systems psychodynamic stance.

Research purpose: The purpose of the research was to use group-as-a-whole to study individual behaviour in organisations.

Motivation for the study: Team research and practice is not on a par with the complexities that teams actually experience. Traditional group interventions use humanistic and functionalistic paradigms that do not consider the unconscious functioning of groups. Interventions that use the system psychodynamic paradigm could address these dynamics because they study behaviour of individual group members in the context of the group-as-a-whole.

Research design, approach and method: The researcher conducted action research in a publishing company. He used purposive sampling and analysed the data using qualitative content analysis.

Main findings: The researcher found that the group-as-a-whole partly explains the behaviour of team members and that intervening from this perspective could improve negative relationships.

Practical/managerial implications: Managers can use interventions that use the groupas-a-whole concept as a diagnostic intervention to study and possibly change the complex behavioural issues that team members experience.

Contribution/value-add: The findings give one an understanding of the behaviour of individual group members when one views it from a systems psychodynamic stance. Furthermore, the researcher proposes a group diagnostic intervention that will allow some of the root causes of poor interpersonal behaviour to surface and group members to diagnose and take ownership of their own behaviour.

\section{Introduction}

Despite the emerging research about the complex nature of team interaction, team research and practice are not on par with the complexities that teams actually experience (Lingham, Richley \& Serlavos, 2009). The purpose of this research was to contribute to the literature on, and practice of, team interventions by reporting on a group intervention from a systems psychodynamic paradigm to address these dynamics.

\section{Background to the study}

Traditionalists view group interventions in organisation development (OD) from three different perspectives. They are:

- a focus on the individual members of the group, or an intrapersonal perspective (singletons), like organisations use in encounter groups

- a focus on the relationship between two members (dyads), or and interpersonal perspective, like organisations use in T-groups

- a focus on the whole group's task performance and process, like organisations use in process consultations (Cummings \& Worley, 2008; French \& Bell, 1999).

The focus of this research was on intervening from the third perspective, the whole group, and from a systems psychodynamic paradigm.

The importance of an open systems perspective in OD is not new and is a developmental stem of the discipline (French \& Bell, 1999; Van Tonder, 2008). However, the OD literature does not account for psychoanalytic object relations theory as a component of groups as psychosocial 
systems (Trist \& Murray, 1990). Group interventions use humanistic and functionalistic paradigms predominantly. They do not consider the unconscious functioning of groups. Consequently, they are too rigid (Brown \& Starkey, 2000). Guerin (1997) stated:

... teamwork models predominant in the workplace assume conscious dynamics and are not comprehensive enough to describe the complexity of group behaviour. Insights from theory, research, and case studies drawing on psychodynamic constructs have not entered the workplace vernacular. (p. 2)

The gestalt approach is the only type of group intervention in the OD literature that addresses unconscious dynamics systemically. However, organisations seldom use this approach in OD (French \& Bell, 1999). It also uses the behaviour of the individual member of the group as its basis and not the group as a context for the behaviour (Hayden \& Molenkamp, 2003).

Unfortunately, the choice of a paradigm does not use the needs of clients as its basis. Instead, it uses the theoretical orientation and training of consultants (Bazigos \& Burke, 1997). They point out that OD consultants generally prefer working with people from a humanistic paradigm.

Therefore, the potential of OD interventions to addresses behaviour holistically, namely from a psychological and systemic perspective, as integrated in the systems psychodynamic paradigm, appears to be unknown, or organisations do not consider it as an OD stance. Because the 'group-as-a-whole' (Woon, 2002) concept uses the systems psychodynamic paradigm of organisational behaviour as its basis, group interventions that use this paradigm could add to our understanding of the complex dynamics and the reasons for poor relationships more completely.

The argument in this research is that one can partly ascribe the individual behaviour of team members to the functioning of the group-as-a-whole that serves as a context for the behaviour, and that intervening from this perspective might improve poor interpersonal behaviour.

\section{Research purpose}

The purpose of the research was to use the group-as-awhole as a context for the study of individual behaviour in organisations.

\section{Trends from the research literature}

\section{Systems psychodynamics}

Systems psychodynamics is the collective behaviour within and between groups, organisations and communities (Neumann, 1999). It is an interdisciplinary field that integrates perspectives from open systems theory, the practice of psychoanalysis as well as group relations theory and methods (Fraher, 2004).

A system is an identifiable gestalt that clear but permeable boundaries delineate (Kast \& Rosenzweig, 1973). It also receives inputs, transforms the inputs and provides outputs to its environment (Van Tonder, 2004). Systems theory made an important contribution to the study of behaviour in organisations. It focused on interdependence as well as the interaction and interconnection between parts of organisations and between organisations, the importance of boundaries between parts of organisations and between different organisations, the role of people within and across boundaries and the nature of leadership in managing these boundaries (Linklater \& Kellner, 2008; Stacey, 2003).

Therefore, systems psychodynamics studies the ways in which unconscious dynamics could negatively affect the rational functioning of organisations. The focus is on surfacing, assessing and interpreting defensive processes in organisations. Awareness of these dynamics could help members of organisations to provide alternative possibilities of behaviour (Dimitrov, 2008).

Anxiety that employees cannot deal with, and therefore block out of their conscious minds, is one of the most important constructs of systems psychodynamics (Stacey, 2003). The need to avoid anxiety largely shapes the nature of a system, including its culture, structure and leadership. Any form of change implies an interruption of the anxiety-containing system and releases anxiety into the system (Linklater \& Kellner, 2008; Obholzer, 1999). This happens especially when organisational aspects, like structure, roles and boundaries, do not adequately contain the anxiety (Hirschhorn, 1993; Obholzer, 1999; Stacey, 2003; Vince \& Broussine, 1996). Like individuals, groups often regress to an infancy stage where family dynamics play out in current authority relations (Klein, 1997; McCollom, 1995; Stokes, 1994). This implies a change for the worse, like deteriorating relationships. The group-as-a-whole then acts as a social defence mechanism to contain the anxiety so that the group can survive (Hirschhorn, 1993; Obholzer, 1999; Stein, 1996).

One can regard the 'boundary' concept, as the psychosocial basis of group structures (Katz \& Kahn, 1978), as one of the most important concepts borrowed from the open systems theory when one conceptualises systems psychodynamics (Fraher, 2004) and as a key concept that links the systems perspective and the use of psychoanalytic concepts (McCollom, 1995). Boundaries determine what belongs to a system and what does not. They give the system structure and regulate the transactions of the system with its environment (McCollom, 1995). Therefore, boundaries are important elements of the identities of people, groups and organisations. They provide a sense of identity and contain sense-giving processes that continuously reform and redefine people, groups and organisations (Vince \& Broussine, 1996).

Secondly, the systems-psychodynamic paradigm borrows perspectives from the practice of psychoanalysis, particularly the work of Sigmund Freud (1921) and the object relations theory of Melanie Klein (1959). Wilfred Bion (1961) applied Klein's theories of splitting and projective identification to groups. His observations of group behaviour led to the development of the field of group relations (Fraher, 2004). 
Splitting refers to separating the loved object from the dangerous one, and love from hate, as ways of surviving. By splitting the good from the bad and clinging to the good, infants preserve their beliefs in good objects and their capacity to love them. This is essential for protecting infants from the hostile world and for survival (Klein, 1959).

Groups use splitting to split the world into camps of friends and enemies (Kets de Vries, 2006). Larger groups split and form subgroups in which people may feel more secure. In a typical fight reaction, subgroups may gang up against authority figures or perceived aggressors, resulting in intraand inter-group conflict (Kets de Vries, 2006). They offer leadership to anyone who is willing to use the in-group, outgroup division and mobilise the aggressive forces against the 'enemies', thereby strengthening the identity of the groups or subgroups (Stokes, 1994). However, this type of leadership is short-lived because of continuous in-fighting, bickering and competition (Bion, 1982). As opposed to fight reactions, groups or subgroups could engage in flight reactions. These reactions are typically flights away from work, challenges or relations that create more anxiety than the group members are willing to deal with (Gabriel \& Carr, 2002; Stacey, 2003).

Whereas splitting refers to separating good and bad objects in the mind, projection is the process in which groups expel split-off feelings and thoughts to the outside world (Wells, 1985). They reject certain parts of the external realities, experiences, feelings, wishes and needs, which are unacceptable to the self, and attribute them to others (Kilburg, 2000). People use projection to blame others for their own uncomfortable feelings or shortcomings. They also suppress anxiety-provoking truths about themselves by seeing their own faults in other people.

Klein (1997) developed the concept of projective identification. This occurs when the projected parts begin to possess, control and identify with external objects or other persons onto which people project the unacceptable parts (Segal, 1973).

External demands and the shortcomings of groups determine patterns of projective identification. The valences or predispositions of the individual members to participate in certain unconscious group processes also do so. Valence depends on people's psychological and social identities. Psychological identities refer to people's relatedness with themselves and the external world whilst social identities use demographic characteristics like gender, race, ethnicity and status as their bases (Wells, 1995). Valences provide cues to groups about the valences of their individual members and draw the members of groups into particular types of projective identification and attribution.

Bion $(1961 ; 1982)$ provided an extended and more specific application of the concepts of splitting and projective identification to groups, called basic assumption groups. Basic refers to the survival motive of groups, whilst assumption refers to the fact that the survival motive does not use reality as its basis, but the collective projections of the group members (Banet \& Hayden, 1977). Therefore, groups function on two levels: the sophisticated work group level that is orientated toward overt task completion and the basic assumption level that sometimes supports, but more often hinders, the overt task by acting out these projections (Bion, 1961).

Thirdly, the theory and practice of group relations also strongly influences systems psychodynamics (Fraher, 2004), specifically as the Tavistock Institute (Hayden \& Molenkamp, 2003) applies it. Group relations, the study of the dynamics of groups as holistic systems (Hayden \& Molenkamp, 2003), have a foundation of three theoretical contributions. They are the methods of experiential learning (based on the work of Kurt Lewin), using the self as an instrument (based on the discoveries of Bion) and the group-as-a-whole concept, as Le Bon and McDougall introduced it (Fraher, 2004).

The intervention this research discusses uses the systemspsychodynamic stance that the Tavistock Institute in the United Kingdom (UK) developed. The article discusses the group-as-a-whole concept in more detail.

\section{The group-as-a-whole}

The practice of group relations, as the so-called Tavistock model or Leicester Conferences applies it, is a movement away from psychoanalysis toward examining the groupas-a-whole (Dimitrov, 2008; Fraher, 2004). The systems psychodynamic literature describes the group-as-a-whole concept as the invisible group (Agazarian \& Peters, 1981), the group mind (Erlich, 2001) or the unconscious mind of the group (Stacey, 2003).

The group-as-a-whole refers to the psychosocial aspect of a formal task group, or the behaviour of the group as a social system, and the relatedness of the people with that system (Wells, 1985; 1995; Woon, 2002). An unspoken, unconscious agreement binds group members (Bion, 1961) and their interactions together form a gestalt, or wholeness, that functions as the existential core of the group (Rosenbaum, 2004). Individual members represent aspects of the group's unconscious mind through which the group-as-a-whole can express and understand its life (Wells, 1985).

For example, a group can resolve internal conflict by projecting that conflict onto central figures. The group can influence or manipulate the behaviour of these central figures, leading to rigid role differentiation, role suction (manipulating members in specific roles) and eventually scapegoating. Members, who are bearers of unwanted emotions, often end up as victims of the group's active attempts to reject those ideas and feelings, with destructive consequences for the scapegoat and unsatisfactory solutions to the problems of the group. The group-as-a-whole could then contribute to a distortion of the external reality of the formal work group (Lazar, 2004). Figure 1 presents the dynamics of the groupas-a-whole. 
Dynamic 5

Affective, symbolic, instrumental and other functions are allocated to group members, resulting in role differentiation, role suction and group culture $\uparrow$

\begin{tabular}{|c|c|}
\hline $\begin{array}{c}\text { Dynamic } 4 \\
\text { Group members develop as a tacit, unconscious and collusive lattice (organised } \\
\text { set of connections) }\end{array}$ \\
\hline$\uparrow$ \\
\hline Dynamic 3
\end{tabular}

Projective identification occurs whereby group members function as repositories for each other's projections $\uparrow$

Dynamic 2

Regression leads to splitting as a defence mechanism against anxiety $\uparrow$

Dynamic 1

Anxiety is experienced within group members, leading to regression

\section{ORIGIN}

Developmental theory as root for the group-as-a-whole

Source: Wells, L. Jr. (1995). The group-as-a-whole: A systemic socioanalytic perspective on interpersonal and group relations. In J. Gillette \& M. McCollom (Eds.), Groups in context A new perspective on group dynamics, (pp. 49-85). Lanham: University Press of America.

FIGURE 1: The dynamics of the group-as-a-whole perspective.

\section{Intervening from the group-as-a-whole perspective}

Group interventions from a systems psychodynamic paradigm study behaviour from a group-as-a-whole perspective (Hayden \& Molenkamp, 2003). Therefore, the group functions as a gestalt (and not as an individual as in psychoanalytic therapy) and is the target for the intervention, whilst emphasising the unconscious functioning of the group (and not only the rational behaviour of the group) (Dimitrov, 2008; Paul, Strbiak \& Landrum, 2002).

The purpose of interventions is not to change the personalities of people as other self-development programmes try to do. Rather, they hope to provide opportunities to change the key relationships between the group members (Diamond, 1993). According to Vince (2008, p. 93), they are concerned primarily with 'discovering what collective emotions might reveal about an organisation as a system in context'. This discovery will result from the unique insight the group members might gain into the dynamics that influence the functioning of their group and their role in these dynamics (Cilliers, 2000; Eisold, 1985; Hunt \& McCollom, 1994; Stein, 1996). In general terms, an awareness of these dynamics allows people to develop more maturity in understanding and managing the boundary between their inner worlds and the realities of their external worlds - in other words, maturity to authorise themselves in their roles and to become less captive to group dynamics (Miller, 1989).

Based on the purpose of the interventions, the areas of learning pertain to:

- managing physical and psychological boundaries (the ability to distinguish between what belongs to the individual and what belongs to the group)

- exercising authority
- taking up roles and responsibilities

- the role of structure and group dynamics

- exploring behaviour at the time of the intervention (Hayden \& Molenkamp, 2003; Linklater \& Kellner, 2008).

The interventions use experiential learning and add a deeper dimension to Kolb's (1984) well-known model because they mean studying people and their mutual relatedness. More specifically, they allow people to explore anxiety in a relative safe environment.

Participants perceive, reflect and learn from experience so that they can deal with the world in ways that are different to relying on projective identification (Diamond, 2008; Stein, 2004). According to Brown and Starkey (2000, p. 2), learning that promotes critical reflection 'involves the understanding and the mitigation of those ego defences that tend toward a regressive retreat from a changing reality'. The learning also differs from traditional models, with their focus on addressing what is missing in order to address these aspects in future, by focusing on what is happening in the here-andnow of the interventions (Linklater \& Kellner, 2008).

The role of consultants during interventions is to provide a safe environment for learning to occur by managing the boundaries of the task, time and space. Consultants observe the behaviour of the group as it happens in the here-and-now and formulate working hypotheses for the group to work with, to accept or to reject (Lawrence, 1979). Consultants use the self as an instrument for observation and reflection (Diamond, 2008) and should be aware of transference and countertransference dynamics during the intervention in order to discriminate between their personal defensive predispositions and the unconscious dynamics of the groups (Dimitrov, 2008).

Consultants help the group to identify and examine the unconscious dynamics of the group itself and prevent its members from rescuing one another by working through the dynamics in a flight towards action focused on the future (Linklater \& Kellner, 2008). However, consultants will draw attention to the behaviour of the group-as-a-whole and point out how the group uses its members to express its own emotions, how it exploits some members so that others can absolve themselves from responsibility (Rice, 1965). This type of consultation is also called working with the 'gut of organisations' (Long \& Newton, 1997), 'the organisation in the mind' (Clarkson, 1997), 'struggling with the demon' (Kets de Vries, 2004) and 'working below the surface' (Huffington, Armstrong, Halton, Hoyle \& Pooley, 2004).

Smith, Miller and Kaminstein (2004) refer to an example of such an intervention that the Business School of the University of Pennsylvania conducted in South Africa for senior leaders to address racial tension. According to these authors, the consultants' ability to contain the anxiety, hopelessness and projections enabled the participants to function independently and in an adult manner after the intervention. 
There is also an example in the literature where consultants introduced similar concepts as part of a leadership development programme in South Africa (De Jager, Cilliers \& Veldsman, 2003). Although the programme included experiential learning, the extent to which the programme addressed the group as the context for individual behaviour is not clear.

In a similar example, consultants applied Bion's theory of groups during a training programme for a top management team. They found that the psychological depth of the intervention increased and that dysfunctional basic assumption behaviour prohibited the group from effectively accomplishing the task of the work group (Paul, Strbiak \& Landrum, 2002).

\section{What will follow}

The researcher discusses research design and then reports the findings of the research. He then discusses the findings, interprets them and integrates them with the relevant literature.

\section{Research design \\ Research approach}

The researcher used a qualitative approach. He chose this approach because it provides a unique contribution to the study of organisational issues (Brewerton \& Millward, 2001; Cassell \& Symon, 2004; Von Rosentiel, 2004) and has some advantages over quantitative studies.

It is a scientific approach for gathering information and reflection. It also accounts for unconscious dynamics (Vanheule, 2002). The research relied mainly on an interpretative and constructivist epistemology. This choice is consistent with the research strategy that the article covers next (Myers, 2011).

\section{Research strategy}

The researcher chose action research as the research method because it has historical and conceptual roots for studying group behaviour from a systems psychodynamic paradigm (Bion, 1961). Secondly, the research project had two purposes. They were to intervene deliberately and, at the same time, to study the effects of the intervention (Myers, 2011).

The researcher applied two stages of the action research process (Brewerton \& Millward, 2001). The diagnostic stage consisted of a collaborative analysis of the situation and formulating theories about the nature of the research domain. The therapeutic stage involved collaborative change and studying its effects (Myers, 2011).

The research was explanatory because it provided an explanation of individual behaviour from a systems psychodynamic paradigm.

\section{Research method}

\section{Research setting}

The researcher set the study in a publishing organisation that had 70 employees. The primary task of the organisation was to produce and circulate printed media. The organisation had four divisions. They were Editorial, Production, Marketing and Administration. Its management consisted of the general manager, the assistant general manager (who was also the personnel manager), the editor, the news editor (who was also the subeditor), the production manager, the marketing manager and the administrative manager. The editorial team, consisting of 17 members (12 White women, 3 White men and 2 Black men), was the target of the intervention.

The organisation provided the information that follows about the post of editor. The current editor, who had been in the position for eight months, was the third incumbent in five years. On appointment, the organisation informed her that the department was functioning well with competent personnel. However, she had to improve the discipline because of the management styles of the previous editors.

After the previous editor's resignation, in unfavourable circumstances, the news editor (subeditor) had acted successfully in the post. She applied for the post but the organisation did not appoint her. According to the top managers, she had managed the department well and there were good interpersonal relations, but she was too young for the post.

The next editor occupied the post for only three months and resigned, again in unfavourable circumstances. With the post again vacant, the organisation offered the post to the subeditor, whom it had previously thought was too young, but she declined. It then appointed the current editor.

At the time of the intervention, the current editor had been in the post for 10 months. After her appointment, a number of journalists resigned, giving the management style of the editor and her lack of interpersonal skills as their reasons. The organisation began disciplinary action against her. The organisation gave her a written warning and gave her the opportunity to improve her management style and her relationships with her personnel within six months, after which the organisation would reassess her performance.

The diagnostic stage: As part of the diagnostic stage, the researcher conducted interviews with the 17 members of the editorial team to determine whether there was any improvement in the editor's management style and interpersonal behaviour.

During the action planning, the researcher considered two options with the managers. They were to dismiss the editor or to conduct an intervention for the editorial team to explore the dynamics that were influencing the behaviour of the editor as a member of the group. After providing a theoretical 
discussion of the group-as-a-whole concept, they decided to proceed with the second option.

The therapeutic stage: As part of the therapeutic stage of the action research project, the researcher conducted an intervention from the group-as-a-whole perspective. The 17 members of the editorial team attended. He conducted the intervention over two days. It involved eight one-and-a-half hour sessions.

The researcher clearly stated the objectives of the intervention, discussed the roles of the researcher and the participants during the different sessions and applied the group-as-awhole approach.

Six sessions involved experiential learning and two (the last session on each day) entailed reflection, application and debriefing.

The researcher determined the effects of the intervention by conducting interviews after the intervention.

\section{Entrée and establishing researcher roles}

The researcher acted as systems psychodynamic consultant. Six months after the written warning, the human resources manager approached him to find out if there had been any improvement in the editor's management style and interpersonal behaviour. The intention of the managers was to make a fair decision because they were considering dismissing the editor.

The researcher also acted as interviewer during the diagnostic phase in the presence of the personnel manager. The researcher and manager provided joint feedback on the diagnosis and action planning. The researcher conducted the intervention and the later interviews.

\section{Sampling}

The researcher interviewed the 17 members of the editorial team during the diagnostic stage of the project. They all attended during the therapeutic stage.

For the evaluation interviews that followed the intervention, the researcher used purposive sampling, aimed at maximal variation (Flick, 2002). Variation used the team members' responses before the intervention. The sample consisted of four respondents (all White women). One of them had apparently had the worst experience of the editor's management style. Another apparently had not had much of a negative experience. The other two were the editor and the subeditor.

\section{Data collection methods}

The researcher used unstructured interviews (Fossey, Harvey, McDermott \& Davidson, 2002) in the diagnostic phase of the project to determine whether the behaviour of the editor had improved after she received the written warning.
The intervention also served as a measuring instrument. During the intervention, the researcher collected data by observing the behaviour of the group-as-a-whole and by noting the researcher's experience of transference and counter-transference, especially during the experiential sessions. He used in-depth interviews (Babbie \& Mouton, 2001) to collect data during the evaluation phase after the intervention to determine the effects of the intervention.

\section{Recording of data}

The researcher recorded the data from all the diagnostic and evaluation interviews using a digital recorder and transcribed them. He noted the working hypotheses he identified during the intervention.

\section{Data analysis}

The researcher analysed the data manually using qualitative content analysis (Babbie \& Mouton, 2001; Spencer, Richie \& O'Connor, 2003).

It involved two levels of analysis. The researcher reviewed, identified and coded recurring themes in the data for each participant and then for all participants. He then integrated the themes into a meaningful hypothesis (Fossey, Harvey, McDermott \& Davidson, 2002).

Whilst analysing the data he obtained during the intervention, the researcher focused on discovering, using the working hypotheses (Vanheule, 2002). Whilst analysing the data he obtained from the evaluation interviews, the researcher focused on meaning (Fossey, Harvey, McDermott \& Davidson, 2002).

The researcher acknowledged the influence of the data collection process on the data analysis in this research because one cannot use these two processes in isolation when conducting qualitative research (Taylor \& Bogdan, 1984).

\section{Strategies employed to ensure quality data}

The researcher applied the framework Lincoln and Guba (1985) developed to ensure quality data. He improved trustworthiness by engaging for long periods with the client system to build trust and to understand the context.

The participants who were involved in the research also checked the interpretations and conclusions.

In addition, the researcher documented the research project in detail to help readers to determine the transferability of the findings to other contexts. He reported on this in the description of the setting of the research.

The researcher ensured confirmability by consulting a colleague who is trained in working from a systemspsychodynamic perspective in organisations, but who was not part of the research project. A colleague, who is an OD expert but had no training in systems psychodynamics, 
conducted another audit. This also helped the researcher to reflect on the influence of his personal bias on the findings.

The researcher achieved triangulation by establishing congruence between the data he obtained from the intervention and the data he obtained from the evaluation interviews.

The researcher clarified ethical aspects about the intervention continuously during the project. He obtained informed consent for the whole project from the managers and from all the members of the editorial team. He also obtained permission to use the project for research. The organisation and the interviewees granted permission to record the interviews and to use the information for research.

\section{Reporting}

The researcher tried to use the same phrases, words and key terms that the respondents used to substantiate the themes. As some responses were in Afrikaans, he used a qualified translator to translate the Afrikaans transcriptions into English as accurately as possible.

\section{Findings}

In order to determine how the group-as-a-whole served as the context for understanding the behaviour of individual members, the researcher first reported on the themes he identified from the diagnostic interviews, followed by the themes that emerged from the intervention. To determine whether the intervention positively changed the functioning of the group, the researcher reported on the themes he identified from the evaluation interviews.

\section{Themes from the diagnostic interviews}

Theme 1: The manager (editor) displays negative interpersonal behaviour

There was strong evidence that showed that the respondents still experienced the interpersonal behaviour of the manager (after six months) very negatively. The only positive theme the researcher identified from the interviews was her 'excellent administration'. The few respondents, who experienced a slight improvement after her warning, were still very sceptical about her management style and interpersonal behaviour.

The subthemes that follow emerged.

Subtheme 1a - The manager has poor interpersonal relations: The researcher found that respondents experienced her interpersonal behaviour as poor in statements like 'I am scared of her', 'She is our enemy' and 'She makes mistakes, then she blames others'.

Subtheme $1 \mathrm{~b}$ - The manager has poor communication skills: The respondents thought that the manager had poor formal and informal communication skills. One respondent mentioned that a lack of communication influences her work performance: 'I don't get the info that is needed - then my work is at stake'. Another mentioned that 'she is very vague' and another emphasised that it was difficult to talk to her.

Subtheme 1c - The manager shows a lack of respect and acknowledgement: The researcher found substantial evidence that the manager did not respect or acknowledge the respondents. For example, one respondent mentioned that 'only my mistakes are pointed out'. Some of the respondents also experienced the manager's lack of respect and failure to acknowledge others on a personal level in a statement like 'I am not treated like a human being'. One respondent referred to a derogatory comment that the manager made and mentioned that 'I have learnt not to take her seriously'.

Subtheme 1d - There is a lack of mutual trust: The lack of mutual trust is evident in statements like 'she will use things against you' and 'she is paranoid'. More specifically, one respondent summarised her experience as 'there is no trust relationship'.

Subtheme 1e - The manager has excellent administration skills: A number of respondents mentioned a positive aspect of the manager's performance. This was her skill as an administrator. One respondent even referred to her 'excellent administration'.

\section{Theme 2: The manager has an autocratic management style}

The researcher found substantial evidence that showed that the manager had an autocratic management style. Respondents described her style in words like 'dictator', 'eagle-eye' and 'policeman'.

\section{Theme 3: The work climate has improved slightly but scepticism still prevails}

The researcher found enough evidence to indicate that the work climate had improved slightly. However, respondents were sceptical about the sustainability of the improvement. One respondent recognised that 'she puts in more effort, but I don't know how long it is going to last'. Another respondent stated 'it looks as if she tries, but it still is superficial'.

\section{Theme 4: Respondents threaten to resign}

A number of the respondents referred to possible reactions to her behaviour. For example, four threatened to resign, one mentioned that she was going on maternity leave, one respondent said that she wished she would fall pregnant and another received permission to move her office to the technikon.

The conclusion the researcher reached, using the evidence from the diagnostic interviews, is that the extent of the mutual mistrust, which had probably prevailed for a long time, would make meaningful relationships in the future extremely difficult. Even if the manager did change her behaviour significantly, the respondents' perceptions of her would have been difficult to change, especially the perceptions of the personnel who had had very negative experiences with her. These conclusions became the problem statement for the intervention in the action research project. 


\section{Themes derived from the intervention}

\section{Theme 5: There was uncontained anxiety in the department}

Most of the members in the department experienced excessive anxiety. The researcher also experienced it during the project, especially at meetings with managers.

A number of factors caused the anxiety. They included:

- uncertain employment, especially amongst personnel who were still on probation

- possible dismissal

- fears that the general manager and the personnel manager felt that there would be more resignations

- the nature of the work.

A number of factors did not provide enough containment for employees' anxiety. They included:

- the vague formal boundaries of the organisation (because journalists mostly work outside the premises)

- the lack of strict rules for their work because journalists often work closely with members of the public and other organisations

- open space offices

- daily adherence to strict deadlines.

Theme 6: Family dynamics, as a defence mechanism against the anxiety, affected their functioning as a workgroup negatively

Family dynamics also played an important role. The system regressed to an infancy stage where family dynamics played out in current authority relations.

The researcher found examples in the symbolic language the subeditor used during the intervention. She referred to her father as the 'patriarch' and to her mother as 'overcompensating'. The youngest person referred to herself as the 'baby' and 'physically the smallest' when she recounted her experiences of the editor treating her as a baby in the department. During the intervention, she also sat on the floor, eating a lollypop. Other examples included terms like 'rebellious and well-behaved children', 'jealous about relationships' and 'blue-eyed girl'.

Theme 7: Splitting and projective identification as defence mechanisms to contain the anxiety

The dynamic that the researcher worked with during the intervention was that there was a split between good and bad in the fantasy world of the system. The editor (because of her valence) became the bad father figure and the subeditor became the good mother. The unconscious fantasy is that the father and the mother cannot both have good and bad characteristics.

For example, the researcher found evidence of this dynamic when respondents called the editor the 'bad cop' and the subeditor the 'good cop'. The subeditor mentioned that the editor asked her to do the 'fighting' because she (the editor) did not want the employees to see that she was really awful.
The subeditor also mentioned that she found it very difficult to reprimand personnel. When she did, it created conflict between her and her colleagues. The respondents often compared their negative experiences of the editor with the positive experiences they had with the subeditor.

\section{Theme 8: Threats of flight reactions}

The researcher interpreted resignations and threats of resignations, as well as possibilities of maternity leave and jokes about these, as fight-flight reactions. The group often tried to force someone into an unconscious leadership role to fight on behalf of others in very difficult situations.

\section{Theme 9: Group boundaries influenced the functioning of the department}

This theme dealt with how the appointment of the editor threatened the identity of the department. The department formed a close informal team with strict boundaries around them and the subeditor as their informal leader. They unconsciously made it very difficult for any 'outsider' to cross the boundary and become part of the informal group. Several participants mentioned that they trusted the subeditor and would rather approach her with their problems.

The subeditor also mentioned that she had been annoyed when the organisation had not appointed her as editor. These dynamics, together with the expectations that the editor should improve discipline, made managing the department even more difficult. The editor mentioned, on numerous occasions, how difficult she found it to become a member of the team. She also mentioned the difficult demands the managers made. Sometimes she sat on the floor during the intervention.

The researcher realised that the systems-psychodynamics that were influencing the relations in the department would, given the personality of the editor (her valence to identify with their projections), make it almost impossible to manage the department if the organisation did not deal with these matters.

Therefore, the team attempted to resolve the internal conflict by projecting that conflict onto an authority figure whose behaviour the group influenced. The role of the subeditor, as 'fight leader', probably led to rigid role differentiation and the editor becoming the scapegoat. It was clear from Theme 1 that the editor had a strong valence to accept and internalise negative projections. However, addressing the issue on an individual level, or even dismissing the editor, would not have resolved the problem for the organisation because the pattern would probably repeat itself as a repetitive compulsion (as had already happened in the past).

\section{Themes from the evaluation interviews}

Theme 10: The intervention acted as an experiential learning process and led to self-authorisation

The respondents mentioned that they now insisted on their rights and would confront the editor. The most junior member in the department mentioned that 'I am not the baby 
anymore.... I now have a much more adult role ... I now have many responsibilities ...'.

Therefore, she was able to acknowledge her role in the negative working climate without resorting to splitting and projecting or blaming everything on the editor.

\section{Theme 11: Attempts to manage boundaries}

With regard to personal boundaries, one respondent mentioned that ' ... I think I have changed. I keep my nose out of other people's business. I sit in my corner and do my work'. Another referred to the other members by saying 'Everybody talks for himself, everybody is his own person'. With regard to the group's boundaries, one respondent said, with reference to the editor, 'It is like a clique ... It is easy to have a closed clique. It is difficult to get in, but I really think now, they have accepted her ...'.

\section{Theme 12: Attempts to manage boundaries might have lead to role-differentiation}

The subeditor spoke about how she differentiated between her role as a friend to the other group members and her job, and that the members do not 'try me anymore'. The editor mentioned that 'there is now certainty about who is the editor. They now look at the position and not at the person... they feel free to talk to me, but they don't joke with me ...' and that the 'good cop-bad cop dynamic' did not exist anymore.

The findings of the evaluation interviews supported, and are consistent with, the findings the researcher derived from the intervention.

Based on the evaluation interviews, the employees experienced a positive shift in the conflict process. Therefore, the intervention provided an alternative way of dealing with overt conflict.

Addressing these group dynamics probably resulted in greater optimism amongst personnel, more openness about communication, especially between the editor and other members of the department and a more positive working climate.

The intervention enabled the department to function more effectively as a team and probably contributed to achieving three awards: one for the best newspaper in a specific category.

Therefore, the intervention, from the systems psychodynamic stance, helped to create awareness, in the group members, of the group-as-a-whole as the context for studying individual behaviour and that acknowledging their own contributions to these dynamics led to self-authorisation, attempts to manage their personal boundaries and better role differentiation.

\section{Discussion}

The purpose of the research was to use the group-as-a-whole as the context for the study of individual behaviour in an organisation. The research project related to the study of complex organisational behaviour, attributed to the negative interpersonal behaviour of a manager. Action research was the vehicle for creating consciousness about, and possibly changing, some of the root causes of the behaviour.

After studying the themes he identified from the diagnostic interviews, together with the themes he derived from the intervention, the researcher hypothesised that studying behaviour (using a systems psychodynamic intervention) from the group-as-a-whole perspective provides a unique contribution to understanding individual behaviour.

Studying behaviour from an individual perspective only would lead to attributing the poor interpersonal relations, communication problems, autocratic management style and negative work environment to the behaviour of the editor. However, studying behaviour from the group-as-a-whole perspective acknowledges the existence of basic assumption group behaviour that acts as a defence mechanism against anxiety and to the possibility that splitting, projections and projective identification influenced the behaviour of the staff members.

This interpretation supports the systems psychodynamic literature on team behaviour (Bion, 1961; 1982; Hirschhorn, 1993; Linklater \& Kellner, 2008; Obholzer, 1999; Stacey, 2003; Vince \& Broussine, 1996). Attributes that one often ascribes to individual team members, especially negative attributes, often contain projections that are beyond the awareness of individual and other team members (Wells, 1985). Therefore, the group-as-a-whole perspective places the behaviour of individual group members into a systems-psychodynamic context and partly explains that behaviour.

When two people are involved in conflict, one normally assumes that the two (using an interpersonal perspective) are the targets for diagnosis and intervention (French \& Bell, 1999). When almost all subordinates share similar strong feelings about their manager, one often sees this as enough evidence that the individual (manager) is the target for diagnosis and intervention.

When one uses an individual or interpersonal perspective, one would have regarded an intervention to address the management or leadership skills of the editor, or even the interpersonal or conflict-handling skills of the group members, as appropriate.

However, such interventions (possibly growth, gestalt or T-group) would not have addressed the behaviour of the person in the context of the group-as-a-whole. They would not have allowed the manager to become aware of her valence to identify with these projections (in terms of her authority position and her personality characteristics). Similarly, the other members would not have been able to acknowledge their own contributions to the dynamics (their projections) that form the context or to make empowered decisions about their unconscious roles that kept the dynamics intact. 
One can argue that the dynamics that influenced the relations in the department would have, despite the personality of the editor (her valence to identify with their projections), made it almost impossible to manage the department if the organisation did not deal with them.

It was clear from the diagnostic interviews that the editor had a strong valence to accept and internalise negative projections. However, to address the issue on an individual level, or even to dismiss the editor, would not solve the problem for the company because the pattern would probably repeat itself. The resignation of the former editors confirmed this. This perception is consistent with the view of Lazar (2004), who argued that, if one diagnoses individual behaviour in the context of the group-as-a-whole, attempts to solve it by other means would probably not succeed.

One can regard the intervention that used the group-as-awhole perspective as a diagnostic intervention because the themes the researcher identified during the intervention led to an added perspective on the previous diagnosis of this project: that the dynamics of the context had a significant influence on the editor's behaviour.

The themes the researcher identified in the evaluation interviews tested the appropriateness of this diagnosis. The themes showed that the respondents experienced a positive shift in the group dynamics, leading to a task group that functioned better. An awareness of the-group-as-a-whole as the context for studying individual behaviour, and an acknowledgement of their own contributions to these dynamics, probably resulted (on an interpersonal level) in greater optimism amongst personnel, more openness about communication, especially between the editor and other members of the department, and a more positive working climate.

The intervention enabled the department to function more effectively as a team and probably contributed to achieving three awards, one for the best newspaper in a specific category. This interpretation is consistent with the purpose of the intervention, which was to provide an insight into the covert dynamics that influenced the functioning of the group (Huffington, Armstrong, Halton, Hoyle \& Pooley, 2004). An awareness of these dynamics enabled group members to develop more maturity in understanding and managing the boundary between their inner worlds and their external realities, to manage themselves in their roles and to become less constrained by group and organisational dynamics (Miller, 1989). It was only after they became aware of their own roles in the group, by studying their own behaviour in the context of the group-as-a-whole during the intervention, that it became possible to change their behaviour (Miller, 1989; Stein, 2004).

Therefore, one can argue that an intervention that uses the group-as-a-whole as its context for individual behaviour is a group diagnostic intervention (French \& Bell, 1999) and has the advantages that follow:
- participants are involved in the diagnostic process and allows them to own problems and solutions

- growth and change occur during the intervention because they allow participants to acknowledge projections

- diagnosis and intervening happens simultaneously as part of the same process and this makes it possible to reduce the unfulfilled expectations that participants often experience after diagnosis.

This type of OD intervention is consistent with the views of interventions that Diamond (2008) and Van Tonder (2008) conceptualised. Diamond (2008) stated that:

genuine organizational change (i.e., change that affects culture and identity, not simply strategies and structure) is rooted in the character of self and other relations in the context of the organization. (p. 357)

Using the group-as-a-whole as a diagnostic intervention differs from other group diagnostic interventions because, instead of identifying and analysing 'the problem', the consultant will rather ask questions about the functional role of 'the problem' in the systemic context of the groupas-a-whole. For example, the consultant, together with the target group, attempted to understand how and why they put certain members in certain roles in certain circumstances.

In conclusion, the hypothesis the researcher formulated is that one can ascribe the individual behaviour of team members partly to the functioning of the group-as-a-whole that serves as the context for the behaviour and that intervening from this perspective might improve negative relationships.

\section{Possible limitations of the study}

The researcher did not explore the influence of the larger system as a context for the department. For example, exploring the dynamics between the editor and her managers could have thrown more light on the accuracy of the hypothesis.

Although the researcher chose the sample for the evaluation interviews carefully, it was still very small. He could have included a man as well.

The research reported on one project only. Including similar projects could provide more evidence of the extent to which projections target managers because of their authority roles or their personalities as both are sources of valence.

\section{Practical implications of the study}

The findings have the practical implications that follow:

- researchers should study the complex behaviour of team members in the context of the group-as-a-whole

- one can regard the group-as-a-whole approach as an appropriate group diagnostic intervention, especially when scapegoating and marginalising individual group members occurs

- OD consultants need training in the systems psychodynamic paradigm in order to work with the group-as-a-whole concept because many do not regard 
it as a 'tool' and consultants who intend using this approach will have to learn how to work with the self as an instrument.

\section{Recommendations for further research}

Research that compares the effects of different small group interventions is needed. Further research can focus on determining whether different cultures (individualistic cultures as opposed to collectivistic ones) will experience interventions from the group-as-a-whole perspective differently.

Finally, research on the valence of members to carry certain projections may shed light on some of the unanswered questions.

\section{Acknowledgements \\ Competing interests}

The author declares that he has no financial or personal relationship(s) that may have inappropriately influenced him when he wrote this paper.

\section{References}

Agazarian, Y., \& Peters, R. (1981). The visible and invisible group. London: Routledge $\&$ Kegan Paul.

Babbie, E., \& Mouton, J. (2001). The practice of social research. Cape Town: Oxford University Press.

Banet, A.G., Jr., \& Hayden, C. (1977). A Tavistock primer. In J.E. Jones \& J.W. Pfeiffer (Eds.), The annual handbook for group facilitators, (pp. 155-167). La Jolla, CA University Associates.

Bazigos, M.N., \& Burke, W.W. (1997). Theory orientations of organization development (OD) practitioners. Group \& Organiization Management, 22(3), 384-408. http:// dx.doi.org/10.1177/1059601197223005

Bion, W.R. (1961). Experiences in groups. London: Tavistock. http://dx.doi. org/10.4324/9780203359075

Bion, W.R. (1982). Group dynamics: a review. In S. Scheidlinger (Ed.), Psychoanalytic group dynamics, (pp. 77-107). New York: International Universities Press.

Brewerton, P., \& Millward, L. (2001). Organizational research methods. London: Sage.

Brown, A.D., \& Starkey, K. (2000). Organizational identity and learning: a psychodynamic perspective. Academy of Management Review, 25(1), 102-132.

Cassell, C., \& Symon, G. (Eds.). (2004). Essential guide to qualitative methods in organizational research. London: Sage.

Cilliers, F.v.N. (2000). Team building from a psychodynamic perspective. Journal of Industrial Psychology, 26(1), 18-23.

Clarkson, P. (1997). Consulting in rapidly changing conditions of uncertainty. In J.E. Neumann, K. Kellner \& A. Dawson (Eds.), Developing organisational consultancy, (pp. 159-179). London: Routledge.

Cummings, T.G., \& Worley, C.G. (2008). Organization development \& change. Mason, $\mathrm{OH}$ : South-Western Cengage Learning.

De Jager, W., Cilliers, F., \& Veldsman, T. (2003). Leadership development from a systems psychodynamic consultancy stance. SA Journal of Human Resource Management, 1(3), 85-92.

Dimitrov, P.L. (2008). Organisational Psychodynamics: Ten introductionary lecturers for students, managers and consultants. Retrieved n.d., from http://www. orgdyne.com/

Diamond, M.A. (1993). The unconscious life of organizations: Interpreting organizational identity. Westport, CT: Quorum Books. http://dx.doi.org/10.1177/ 0021886308317403

Diamond, M.A. (2008). Telling them what they know: Organizational change, defensive resistance, and the unthought known. Journal of applied Behavioral Science, 44(3), 348-364.

Eisold, K. (1985). Recovering Bion's contributions to group analysis. In A.D. Colman \& M. H. Geller (Eds.), Group relations reader, (vol. 2, pp. 37-48). Jupiter: A.K Rice Institute.

Erlich, H.S. (2001). Enemies within and without: Paranoia and regression in groups and organizations. In L. Gould, L.F. Stapley \& M. Stein (Eds.), The systems psychodynamics of organizations (pp. 115-131). London: Karnac Books.

Flick, U. (2002). An introduction to qualitative research. London: Sage.
Fossey, E., Harvey, C., McDermott, F., \& Davidson, L. (2002). Understanding and evaluating qualitative research. Australian and New Zealand Journal of Psychiatry, 36, 717-732. http://dx. doi.org/10.1046/j.1440-1614.2002.01100.x

Fraher, A.L. (2004). Systems psychodynamics: The Formative years of an interdisciplinary field at theTavistock Institute. History of Psychology, 7(1), 65-84. http://dx.doi.org/10.1037/1093-4510.7.1.65, PMid:15025060

French, W.L., \& Bell, C.H. (1999). Organization development: Behavioural science interventions for organization improvement. (5th edn.). Englewood Cliffs: Prentice-Hall.

Freud, S. (1921). Group psychology and the analysis of the ego. New York: Boni and Liveright.

Gabriel, Y., \& Carr, W. (2002). Organizations, management and psychoanalysis: an overview. Journal of Managerial Psychology, 17(5), 348-365. http://dx.doi. org/10.1108/02683940210432600

Guerin, M.L. (1997). Teamwork at Barton Company: A psychodynamic perspective. Paper presented at the 1997 symposium of the International Society for the Psychoanalytic Study of Organizations.

Hayden, C., \& Molenkamp, R.J. (2003). Tavistock Primer II. Boston: AKRICE Institute. Hirschhorn, L. (1993). The workplace within. Cambridge, MA.: MIT Press.

Huffington, C., Armstrong, D., Halton, W., Hoyle, L., \& Pooley, J. (2004). Working below the surface: The emotional life of contemporary organizations. London: Karnac Books.

Hunt, J., \& McCollom, M. (1994). Using psychoanalytic approaches in organizational consulting. Consulting Psychology Journal, 46(2), 1-11. http://dx.doi. org/10.1037/1061-4087.46.2.1

Kast F.E., \& Rosenzweig, J.E. (1973). General systems theory: Applications for organization and management. In F.E. Kast \& J.E. Rosenzweig (Eds.), Contingency views of organization and management, (pp. 37-56). Chicago: Science Research views of organ
Associates.

Katz, D., \& Kahn, R.L. (1978). The Social Psychology of Organizations. (2nd edn.). New York: Wiley \& Sons.

Kets de Vries, M.F.R. (2004). Struggling with the demon: Perspectives on individua and organizational irrationality. Madison, CT: Psychosocial Press.

Kets de Vries, M.F.R. (2006). The leader on the coach: A clinical approach to changing people and organisations. Chichester: Wiley \& Sons.

Kilburg, R.R. (2000). Executive coaching: Developing managerial wisdom in a world of chaos. Washington, DC: American Psychological Association. http://dx.doi. org/10.1037/10355-000

Klein, M. (1959). Our adult world and its roots in infancy. Human Relations, 12, $291-$ 303. http://dx.doi.org/10.1177/001872675901200401

Klein, M. (1997). Envy and gratitude, and other works 1946-1963. London: Vintage. Kolb, D. A. (1984). Experiential learning. Englewood Cliffs, NJ: Prentice-Hall.

Lawrence, W.G. (1979). Introductory Essay: Exploring boundaries. In W.G. Lawrence (Ed.), Exploring individual and organizational boundaries, (pp. 1-19). New York: Wiley \& Sons.

Lazar, R.A. (2004). Experiencing, understanding, and dealing with intergroup and institutional conflict. In L.J. Gould, L.F. Stapley \& M. Stein (Eds.), Experiential learning in organizations, (pp. 137-171). London: Karnac.

Lewin, K. (1951). Field theory in social science. New York: Harper \& Row.

Lincoln, Y.S., \& Guba, E.G. (1985). Naturalistic inquiry. Beverly Hills, CA: Sage.

Lingham, R., Richley, B.A., \& Serlavos, R.S. (2009). Measuring and mapping team interaction.Cross Cultural Management: An International Journal, 16(1), 5-27 http://dx.doi.org/10.1108/13527600910930013

Linklater, J., \& Kellner, K. (2008). Don't just do something ... stand there: using action learning to help organisations work with anxiety. Action learning: Research and Practice, 5(2), 167-172. http://dx.doi.org/10.1080/14767330802185855

Long, S., Newton, J. (1997). Educating the gut: socio-emotional aspects of the learning organization. Journal of Management Development, 16(4), 284-301. http:// dx.doi.org/10.1108/02621719710164562

McCollom, M. (1995). Group formation: Boundaries, leadership and culture. In J. Gillette \& M. McCollom (Eds.), Groups in context: A new perspective on group dynamics. Lanham: University Press of America.

Miller, E.J. (1989). The Leicester model: Experiential study of group and organizational processes. Occasional paper no. 10. London: Tavistock Institute of Human Relations.

Myers, M.D. (2011). Qualitative research in Business Management. London: Sage.

Neumann, J.E. (1999). Systems psychodynamics in the service of political organizational change. In R. French \& R. Vince (Eds.), Group relations, management, and organization, (pp. 54-69). Oxford, England: Oxford University Press.

Obholzer, A. (1999). Managing the unconscious at work. In R. French \& R. Vince (Eds.), Group relations, management and organization, (pp. 112-126). New York: Oxford.

Paul, J., Strbiak, C., \& Landrum, N. (2002). Psychoanalytic diagnosis of top management team dysfunction. Journal of managerial Psychology, 8(17), 381-393. http:// dx.doi.org/10.1108/02683940210432628

Plug, C., Meyer, W.F. Louw, D.A., \& Gouws, L.A. (1988). Psigologie woordeboek. (2de uitg.). Johannesburg: Lexicon.

Rice, A.K. (1965). Learning for leadership. London: Tavistock.

Rosenbaum, S.C. (2004). Group-as-mother: A dark continent in group relations theory and practice. In S. Cytrynbaum \& D.A. Noumair (Eds.), Group dynamics, organizational irrationality and social complexity: Group relations reader 3 , (pp. organizational irrationality and social
$57-79)$. Jupiter, FL: A.K. Rice Institute.

Segal, H. (1973). Introduction to the work of Melanie Klein. London: Hogarth Press. 
Smith, K.K., Miller, R., \& Kaminstein, D. (2004). Consultant as container: Assisting organizational rebirth in Mandela's South Africa. In S. Cytrynbaum \& D.A. Noumair organizational rebirth in Mandela's South Africa. In S. Cytrynbaum \& D. A. Noumair (Eds.), Group dynamics, organizational irrationality and social comr
relations reader 3, (pp. 243-266). Jupiter, FL: A.K. Rice Institute.

Spencer, L., Ritchie, J., \& O'Connor, W. (2003). Analysis: Practices, Principles and processes. In J. Ritchie \& J. Lewis (Eds.), Qualitative research practice: A guide for social science students and researchers, (pp. 199-218). London: Sage.

Stacey, R.D. (2003). Strategic management and organizational dynamics: The challenge of complexity (4th edn.). Harlow, England: Pearson Education.

Stein, M. (1996). Unconscious phenomena in work groups. In M.A. West (Ed.), Handbook of work group psychology, (pp. 143-158). Chichester: Wiley \& Sons.

Stein, M. (2004). Theories of experiential learning and the unconscious. In L.J. Gould, L.F. Stapley \& M. Stein (Eds.), Experiential learning in organisations, (pp. 19-36). London: Karnac Books.

Stokes, J. (1994). The unconscious at work in groups and teams: contributions from the work of Wilfred Bion. In A. Obholzer \& V.Z. Roberts (Eds.), The unconscious at work: Individual and organizational stress in the human services, (pp. 19-27). London: Routledge.

Taylor, S.J., \& Bogdan, R. (1984). Introduction to qualitative research methods: The search for meanings. (2nd edn.). New York: Wiley \& Sons.

Trist, E., \& Murray, H. (Eds.). (1990). The social engagement of social science: $A$ Tavistock anthology, Volume l: The socio-psychological perspective. Philadelphia: University of Pennsylvania.

Turquet, P.M (1985). Leadership: The individual and the group. In A.D. Colman \& M.H. Geller (Eds.), Group relations reader 2, (pp. 71-87). Jupiter, FL: A.K. Rice Institute.
Vanheule, S. (2002). Qualitative research and its relation to Lacanian psychoanalysis. Journal for the Psychoanalysis of Culture \& Society, 7(2), 336-343.

Van Tonder, C.L. (2004). Organisational change: Theory and practice. Pretoria: Van Schaick.

Van Tonder, C.L. (2008). Stacking the dominoes... courting catastrophe at the "edgeof-chaos". Paper presented at the 9th IFSAM World Management Conference, Shanghai, People's Republic of China, 26-28 July.

Vince, R. (2008). 'Learning-in-action'and 'learning inaction': Advancing the theory and practice of critical action learning. Action Learning Research and Practice, 5(2), 93-104. http://dx.doi.org/10.1080/14767330802185582

Vince, R., \& Broussine, M. (1996). Paradox, defense and attachment: accessing and working withemotionsand relationsunderlyingorganizationalchange.Organization Studies, 17(1), 1-20. http://dx.doi.org/10.1177/017084069601700101

Von Rosenstiel, L. (2004). Organizational analysis. In U. Flick, E. von Kardorff \& I. Steinke (Eds.), A companion to qualitative research, (pp. 129-136). London: Sage.

Wells, L. Jr. (1985). The group-as-whole perspective and its theoretical roots. In A.D. Colman \& M.H. Geller (Eds.), Group relations reader 2, (pp. 109-126). Jupiter: A.K Rice Institute.

Wells, L. Jr. (1995). The group-as-a-whole: A systemic socioanalytic perspective on interpersonal and group relations. In J. Gillette \& M. McCollom (Eds.), Groups in context: A new perspective on group dynamics, (pp. 49-85). Lanham: University context: A new persp
Press of America.

Woon, J.M.S.T. (2002). Exploring the underlying dimensions of the group-as- $a$-whole scale. Unpublished DLitt et Phil. dissertation, Columbia University, Ann Arbor, MI. 